\title{
APRENDER E ENSINAR: UM CASO DE AMOR AO MUNDO
}

\author{
Suzana Feldens Schwertner ${ }^{1}$ \\ Cláudia Inês Horn ${ }^{2}$ \\ Belonice Medeiros da Silva ${ }^{3}$
}

\begin{abstract}
Resumo: O presente artigo objetiva discutir sobre os processos de ensinar e de aprender no universo escolar, trazendo à tona três palavras centrais: aprender, ensinar e amar. Tais palavras, tomadas como eixos que transversalizam as possibilidades de potencializar o espaço escolar, estão ancoradas em problematizaçóes desenvolvidas a partir dos estudos teóricos de Biesta (2013), Masschelein e Simons (2014) e Larrosa (2017; 2018). Articuladas a esses estudos, duas obras de Banksy foram selecionadas como intercessores para tensionar o ensino e a aprendizagem na escola. A potencialidade epistemológica aponta para os princípios de incerteza, de autocrítica e auto-reflexão, elementos que perpassam a noção de um ato de aprender e ensinar que acontece no encontro.
\end{abstract}

Palavras-chave: escola; ensinar; aprender; amor.

\section{LEARNING AND TEACHING: FOR THE LOVE OF THE WORLD}

\begin{abstract}
The present article aims to discuss the processes of teaching and learning in the school universe, highlighting three main words: learn, teach and love. These words, taken as axes that cross the possibilities to enhance the school space, are anchored in problematizations developed from the theoretical studies of Biesta (2013), Masschelein and Simons (2014) and Larrosa (2017; 2018). Articulated with these studies, through Banksy's works, the writing produced ways to tension the teaching and school learning. The epistemological potential points to the principles of uncertainty, self-criticism and self-reflection, elements that permeate the notion of an act of learning and teaching that happens in the encounter.
\end{abstract}

Keywords: school; teach; learn; love.

1 Psicóloga (UFRGS). Doutora em Educação (UFRGS). Docente do PPGEnsino da Univates. Docente do curso de Psicologia da Univates.

2 Pedagoga (Univates). Doutora em Educação (Unisinos). Docente no Centro de Ciências Humanas e Sociais Aplicadas da Univates.

3 Graduação em Educação Artística, habilitação em Teatro (UFSM). Mestre em Artes Cênicas (UFRGS). Professora de Arte na rede estadual de ensino. 


\section{INTRODUÇÃO}

O presente trabalho parte de discussões atuais sobre o ensinar e o aprender na contemporaneidade, perguntando: quem ensina e quem aprende na escola de hoje? $\mathrm{O}$ que se faz imprescindível neste processo? Quais os requisitos necessários para aprimorar e movimentar o ensino e a aprendizagem?

Estas foram perguntas que guiaram três pesquisadoras a elaborar este escrito ${ }^{4}$, ancorado em estudos teóricos e de práticas educativas que elas vivenciam em seus cotidianos. Todas estas discussóes foram iniciadas e mobilizadas pelo projeto de pesquisa "XXX" (XXX), no grupo temático "XXX", que desde 2016 vem realizando estudos acerca dos processos de ensino e de aprendizagem em espaços escolares e não escolares. $\mathrm{O}$ presente escrito propóe, então, apresentar problematizaçóes a partir do grupo temático em questão, movimentadas pelo cotidiano acadêmico.

Este exercício teórico realizado pelo grupo constituiu um processo que acolheu olhares atentos e sensíveis, perceptíveis às idas e vindas de falas e escutas dos colegas envolvidos, das perguntas recheadas de olhares questionadores e afoitos pelo encontro coletivo. Encontro que envolveu professoras da universidade, professoras da Educação Básica, estudantes de graduação, estudantes do Ensino Médio, mestrandos, bolsistas de Iniciação Científica. Um processo que envolveu escolhas que articulam diferentes diálogos com o outro e sobre como pensar a escola na contemporaneidade.

A leitura de Gert Biesta (2013) e Jorge Larrosa (2017; 2018) produziu oportunidades de pensar sobre diferentes particularidades que se estabelecem entre sujeitos e o espaço escolar: estudantes, professores, gestores, pais, comunidade escolar. A potencialidade epistemológica destes textos está nos princípios de incerteza, de autocrítica e auto-reflexão. São questôes pertinentes na contemporaneidade, principalmente no que se refere ao ato de aprender e ensinar que acontece no encontro e no sentimento de incompletude, e nos convida, insistentemente, a fazer escolhas.

Para esse artigo, selecionamos três palavras para articular o movimento do nosso pensamento: aprender, ensinar e amar. São elas que abrem o título dessa escrita e que guiam os três movimentos do texto, que passam por apresentar a trilha do grupo temático, as discussóes sobre os processos de ensino na escola contemporânea e o caso de duplo amor ao qual o professor é chamado em sua função docente.

\section{MOVIMENTO - APRENDER: A TRILHA, O PERCURSO, AS ESCOLHAS}

Em 2018, o grupo temático investiu no estudo de duas obras teóricas, amparadas na filosofia da educação. No primeiro semestre, debruçamo-nos no livro

4 O texto parte de uma mesa-redonda apresentada no XXX, realizado XXX, na XXX, cuja participação das três autoras produziu o presente escrito. 
"Para além da aprendizagem: educação democrática para um futuro humano", do holandês Gert Biesta (2013), com o objetivo de desdobrar o desafio proposto pelo autor: compreender e fazer a educação sem uma "essência" em vista (p. 19). Para Biesta (2013), é necessário tratar a questão do ser humano como algo radicalmente aberto, participando ao mesmo tempo em que se caminha pelo processo de educação, sem uma estrada planejada e previamente pavimentada.

Já no segundo semestre de 2018, com o estudo da obra "Elogio da Escola", organizado por Jorge Larrosa (2017), propusemo-nos problematizar as acusaçóes contra a escola: muitos a denominam de normalizadora, colonizadora e alienante, impositiva, reprodutora da ordem social. Contudo, os autores destacam que não querem tomá-la como uma instituição do Estado, nem tratar sobre as frustraçóes da escola: sobre o quanto ela seria enfadonha, disciplinadora, formal, não relacionada ao mundo, excludente. Como afirmam os estudiosos, na apresentação do livro, busca-se falar da escola de modo apreciativo: trata-se de olhar do ponto de vista educacional (LARROSA, 2017, p. 21). E os autores seguem destacando: se busca, enfim, esmiuçar as experiências escolares - e não as experiências institucionalizadas. Para tanto, os autores indicam a leitura de outros dois pensadores da educação, Jan Masschelein e Maarten Simons (2014).

Masschelein e Simons, ao preconizar a defesa da escola, querem tratar sobre algo muito específico; escola seria, para eles um conjunto de "[...] operaçóes efetivas e reais realizadas por um arranjo particular de pessoas, tempo, espaço e matéria. Essas operaçóes são emancipadoras em si mesmas (se a escola não estiver domesticada)" (p. 21). Nessa forma-escola, algumas operaçóes são destacadas: o estudante/aluno, a suspensáo no tempo e no espaço, o tempo livre, o fazer, a atenção. Essa última operação indicada, a atenção, teria como fundamento um amor duplicado, direcionado tanto ao amor pelo mundo quanto ao amor pela nova geração. Conforme Masschelein e Simons:

O que a forma escolar faz (se funciona como uma escola!) é o duplo movimento de trazer alguém para uma posição de ser capaz (e portanto transformar alguém em um aluno ou estudante), o que é ao mesmo tempo uma exposição a algo de fora (e assim um ato de apresentação e exposição do mundo) (MASSCHELEIN; SIMONS, 2014, p. 22).

Mas parece que não é desse modo que temos percebido os investimentos e as apostas no universo escolar. Este texto instala-se num tempo em que a ordem do discurso educacional acostumou-se a falar sobre a falta de comprometimento dos professores para com o ensino, sobre a precarização dos espaços físicos das escolas públicas; acostumou-se a falar sobre metodologias ativas como grande inovaçáo para os processos de aprendizagem, acostumou-se a crer que a salvaçáo do ensinoaprendizagem (escrito com hífen!) está nas novas tecnologias e na digitalização dos processos educacionais. Acostumou-se, sobretudo, a falar sobre competências e habilidades que devem ser trabalhadas na escola para garantir o aprender. Competência para isso, competência para aquilo e uma listagem quase infindável de habilidades a serem desenvolvidas. Contudo, parece que tal ordem do discurso se 
desacostumou a pensar na ordem do encontro, do sensível, dos afetos que rondam o espaço escolar.

A escrita deste texto instala-se num tempo em que avaliaçóes de larga escala, aquelas ditas externas, fazem parte de reunióes pedagógicas e de reestruturações de planejamentos, num tempo em que as avaliaçôes, também aquelas ditas internas, da escola, do professor, proliferam sempre mais, todos os dias letivos, avaliando cada minúcia do aluno na escola. Mas a provocação que se pretende fazer ao nosso pensamento, é pensar por outras vias, desacostumando àquilo que falamos, desconfiando daquilo que todos falam na educação, sobre a educação. Colocar-se às avessas. E nada melhor para colocar-se às avessas do que convidar uma obra de arte para dialogar conosco.

\section{$2^{\circ}$ MOVIMENTO - ENSINAR: QUANDO UMA OBRA NOS ENSINA A PENSAR}

A obra intitulada Love is in the air (stêncil em papel - Figura 1), da autoria de Banksy, artista inglês representante da street art (arte de rua) foi fotografada na exposição The art of Banksy, em 2018, exibida na cidade de Toronto, no Canadá (curadoria de Steve Lazarides). A imagem nos chama atenção pela cor de um vermelho explosivo, seguida de uma postura de ameaça do único sujeito que aparece no quadro: trata-se de um jovem de boné, que tem sua boca e nariz ocultados por um pano escuro (assim como suas roupas). E uma cena que costumamos assistir em meio a protestos em espaços públicos, geralmente em movimentos que reivindicam mudanças de caráter político, econômico e social, bastante comuns nas ruas da América Latina (vide movimentos realizados no Brasil em 2013, na Venezuela em 2018, no Chile em 2019 e, mais recentemente, nos Estados Unidos da América, em 2020 - e vários outros que seguem em ação até o momento de fechamento da escrita desse texto, especialmente considerado a pandemia de Covid-19, que mobilizou o mundo todo) ${ }^{5}$. Em defesa de suas obras, Banksy (2012) afirma que o grafite não é a mais baixa forma de arte, antes o contrário: é uma das mais honestas, pois não há elitismo ou badalação, "[...] o grafite fica exposto nos melhores muros e paredes que a cidade tem a oferecer e ninguém fica de fora por causa do preço do ingresso" (BANKSY, 2012, p. 08).

5 Em 11 de março de 2020 foi declarada a pandemia de Covid-19, uma doença causada pelo vírus Sars-Cov-2, também denominado de "novo coronavírus". Afetando um grande número de pessoas ao redor do mundo, a pandemia de Covid-19 teve como principais modos de mitigação de contaminação o distanciamento social e o uso de máscaras e higienização por meio de álcool em gel. 
Figura 1 - Love is in the air (Banksy, 2008)

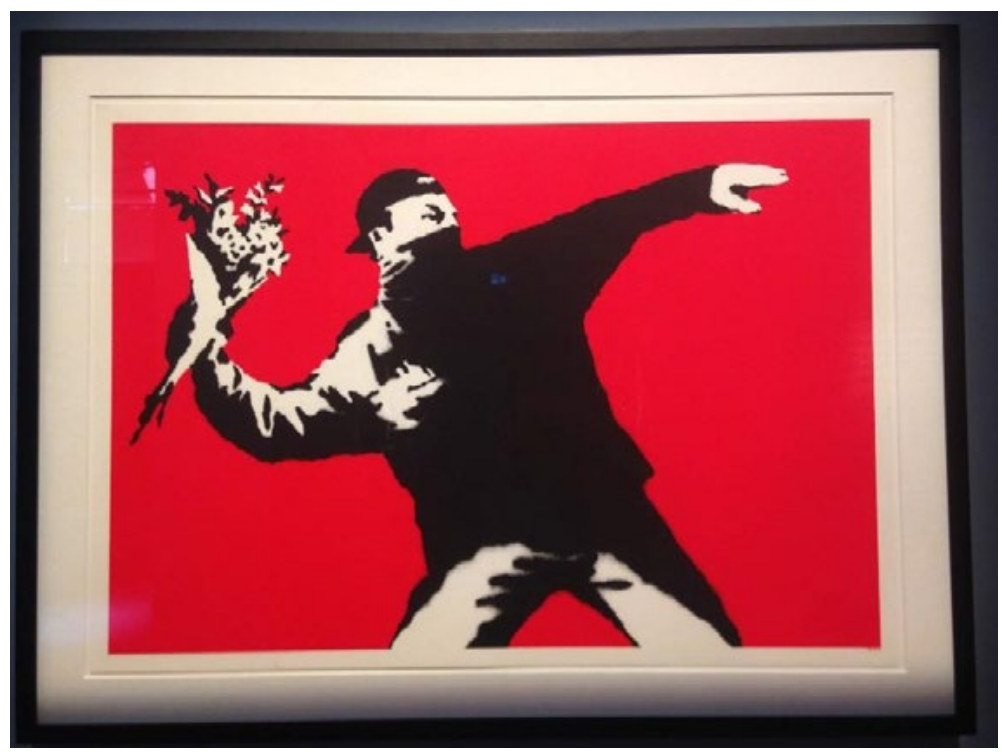

Fonte: XXX (2018)

O artista (ou o coletivo deles) ${ }^{6}$ - há quem insinue que seriam vários artistas, um coletivo de artistas anonimamente distribuídos em várias partes do mundo nos leva para outras tantas reproduçóes possíveis. Love is in the air é uma réplica de uma série de reproduçóes ${ }^{7}$ (igualmente expostas no espaço de arte, em quatro diferentes formatos) de uma obra inicial, produzida em um muro em Jerusalém. Não se trata de qualquer muro, não se trata de qualquer obra: o muro se localiza na divisão entre Israel e a Palestina e o grafitti (Figura 2), intitulado Flower Thrower (ou O atirador de flores, em livre traduçáo) foi elaborado por Banksy em 2003, conforme podemos contemplar na Figura 2.

6 Banksy é definido por Ellsworth-Jones (2013) como mestre do grafttti, pintor, ativista, diretor e provocador "de todos os propósitos". Em 2010, foi considerado uma das 100 pessoas mais influentes no mundo, ao lado de Barack Obama, Steve Jobs e Lady Gaga. Em recente notícia, o artista teria perdido o direito de imagem sobre a obra neste texto mencionada, em virtude de não revelar sua identidade no tribunal. Para maiores informaçóes: https://www.b9.com.br/132232/ banksy-perde-direitos-sobre-a-obra-flower-thrower-por-nao-revelar-sua-identidade-no-tribunal/ (acesso em 11/06/2021).

7 Afirmam haver mais de 150 reproduções desta mesma obra realizada pelo artista. Para maiores informaçóes: https://publicdelivery.org/banksy-flower-thrower/ (acesso em 05/07/2021). 
Figura 2 - Flower Thrower (Banksy, 2003)

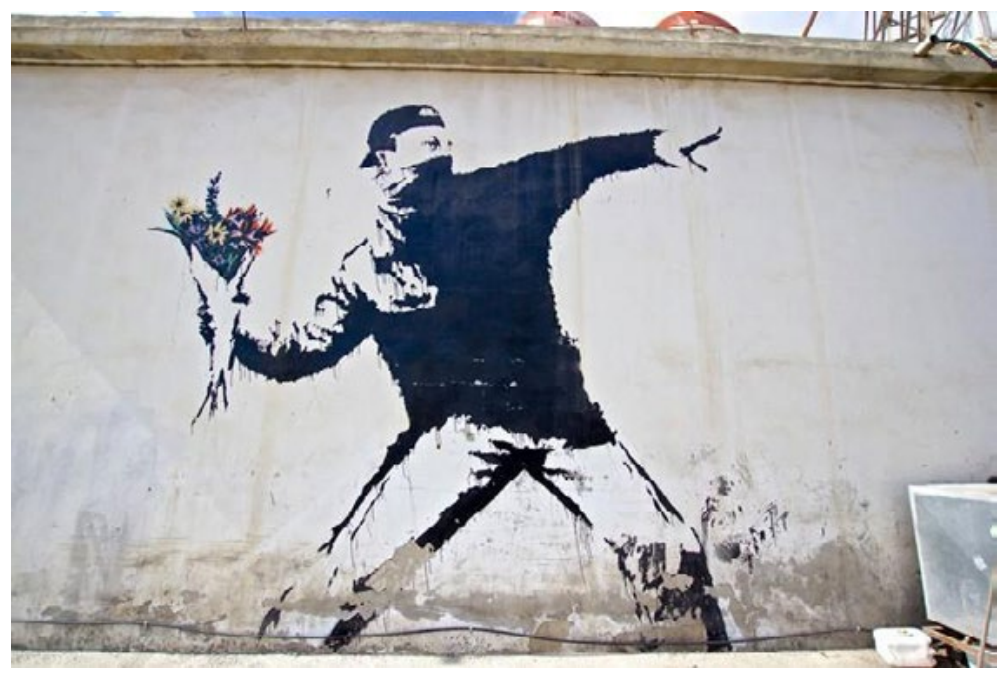

Fonte: https://publicdelivery.org/banksy-flower-thrower/

O jogo de cena proposto pelo artista adiciona um elemento inusitado nas mãos do jovem: ao invés de uma pedra, uma bomba, um cocktail molotov ou artifício perfuro-cortante qualquer que possa produzir um ato de violência, encontra-se na mão direita do sujeito um ramalhete de flores: o amor estará, em breve, literalmente no ar. Ao invés de uma incitação à guerra, um gesto de paz. Chama atenção também que toda a obra é composta por elementos em tons escuros e claros; contudo, as flores do buquê são coloridas. Segundo palavras do artista, que é um desconhecido do público, a arte teria como ação principal confortar o perturbado e perturbar o confortável. Andamos pelo avesso: a postura que chama para um confronto pode também instigar um encontro.

Para materializar este caso de amor faz-se necessário adentrar na poética dos autores citados para potencializar suas vozes que nos apresentam questóes pertinentes e relevantes para pensar a educaçáo e a escola na contemporaneidade, ou seja: "[...] educamos para transformar o que sabemos, não para transmitir o já sabido" (LARROSA; KOHAN, 2013, p. 05).

Neste sentido, "aprender, ensinar e amar" vai ao encontro do movimento de lançar-se e, ao mesmo tempo, estar à espreita de algo, no firme desejo de aproximar o já sabido com o desconhecido. A imagem do atirador de flores sugere "[...] deixarmos de ser o que somos, para ser outra coisa para além do que vimos sendo" (LARROSA; KOHAN, 2013, p. 05).

Quando uma obra nos ensina a pensar acerca do ensino na escola. A redundância das palavras que iniciam a frase deste e do próximo parágrafo é proposital. Podemos dizer que a obra selecionada de Banksy coloca em suspensáo nossos modos de ver e ser no mundo, ao confortar o perturbado e perturbar o confortável. Tal como a escola, que coloca em suspensão, liberta, coloca entre 
parênteses as coisas mundanas, para fazer delas e com elas, outras coisas no espaço e tempo da escola. Pretendemos, aqui, pensar novamente junto com os autores estudados no grupo temático. Masschelein e Simons (2013) afirmam que a escola é uma questáo de suspensão: "O que a escola faz é prover o tempo em que as necessidades e rotinas que ocupam a vida diária das crianças podem ser deixadas para trás" (MASSCHELEIN; SIMONS, 2013, p. 31).

Quando uma obra nos ensina a pensar acerca do ensino na escola, ela coloca em suspensão também nossos pensamentos: a escola, concebida como uma questão de suspensáo, interrompe o tempo, o passado e o futuro, para ocupar-se de um tempo que não é linear. Também o ensino fica suspenso, uma vez que não está à serviço "do ritmo do mundo produtivo"; também os conhecimentos e habilidades ensinadas na escola ficam em suspensão, pois "[...] são trazidos para dentro do currículo escolar, passam a ser matérias e, de certo modo, tornam-se separados da aplicação diária" (MASSCHELEIN; SIMONS, 2013, p. 32).

A partir dessas perspectivas queremos pensar "o que faz da escola ser uma escola": a escola, como espaço social e coletivo, propicia uma acolhida a múltiplas possibilidades de percepçôes e interaçóes entre sujeitos, espaço e tempo e, com isto, desenha açóes transformadoras por meio de experiências construídas na relação com o outro. Sáo escolhas de caminhos que podem acrescentar novos sentidos à educação.

De acordo com algumas narrativas do "Elogio da escola", destacamos aquelas que indicam um olhar diferenciado para a escola, um gesto cuidadoso e, porque não, amoroso com o que acontece no cotidiano escolar: "[...] se queremos transformar a escola em uma questáo pública, trata-se de transformar a escola em uma questáo de preocupação, algo para se prestar a atenção, algo para cuidar" (LARROSA; MASSCHELEIN; SIMONS, 2017, p. 207). Tais proposiçóes revelam o quáo importante é estarmos atentos às novas trajetórias e caminhos que compartilham generosamente o fato de que vale a pena olhar com mais cuidado e de forma amorosa para o cotidiano escolar.

No contexto em que estamos inseridas, como pesquisadoras e professora de Arte, esta reflexão vem ao encontro das inquietaçôes provocadas pelas práticas cotidianas em escolas, principalmente quando estes autores elaboram questōes que não são fáceis de responder e, talvez, algumas não tenham respostas. Acreditamos que práticas pedagógicas experienciadas pelos estudantes na escola proporcionam, acima de tudo, um aprendizado, e que o sujeito, por sua exposição ao que foi proposto, expóe e confronta o seu mundo com o mundo que o rodeia. É a educaçáo como um fim em si mesma, não a serviço de uma função externa.

Nos detivemos, nessa seçáo, provocadas por versôes de uma obra de arte de banksy, a pensar sobre o movimento de ensinar, articulado à sessáo precedente, que pretendeu pensar sobre o movimento do aprender. Tudo isso tem como intenção colocar em suspensão aquilo que fizemos, cotidianamente com os estudantes na escola, na atualidade. Refletir sobre o que "faz de uma escola ser uma escola", ser um organismo vivo, em relação com a vida, é fazer evidenciar isto numa relação 
conjunta e sensível, ou seja, materializá-la num "caso de amor ao mundo", no qual o conhecimento não se encerra e não se deixa aprisionar por verdades prontas e, sim, se constitui num movimento, num vai-e-vem de possibilidades e subjetividades. Eis a palavra amor, para fechar a tríade: aprender, ensinar, amar.

\section{MOVIMENTO - DO AMOR}

Nesta seção, uma vez mais, tratamos de pensar a escola. E para pensar a escola, reiteramos que escolhemos três palavras: aprender, ensinar e amar. Percebam que as palavras aprender, aprendizagem, ensinar, ensino nos acompanham desde o início desta escrita. Contudo, queremos acentuá-las aqui numa outra racionalidade de pensamento; em especial, acerca da palavra amor. Uma palavra suspeita que, conforme Larrosa (2018), juntamente com as palavras vocação, ofício e fé parecem um tanto "[...] envelhecidas, ressecadas e paralisadas" (LARROSA, 2018, p. 126) - mas que podem contribuir para pensar acerca do ofício de professor. Nos distanciamos daquele amor tomado como romantização da educação, aquele postulado, por exemplo, por Rousseau (1979), que sugeria ao professor preceptor amar, adorar as suas crianças, amá-las para educá-las com carinho e ternura.

O amor que abordamos aqui está muito mais relacionado ao a-mor, tomando o prefixo "a" como indicaçáo de negação da morte, tal como nos propóe Jorge Larrosa (2017). Ao negar a morte, acentuamos a vida, a potência, o encontro com o outro, o acontecimento. É a partir dessa lógica que discutimos o aprender e o ensinar na escola. Escola enquanto tempo e espaço que possibilita um encontro com o ensinar e o aprender, enquanto potência de vida.

Talvez o aprender e o ensinar, colados na via da recognição, dão uma forma para a escola: a de acalmar o corpo, para que a alma possa aprender, a de homogeneizar modos de ser aluno, acreditar que só aprendemos aquilo que alguém nos ensina, este alguém mais experiente, conhecer do mundo das ideias, geralmente, o professor. É ele quem ensina na escola, preferencialmente, as mesmas coisas, para todos os alunos; preferencialmente, espera que todos aprendam ao mesmo tempo e no mesmo espaço. O que importa aqui é o saber, um saber que se manifesta em provas, testes, trabalhos em grupos; um saber que é passível de avaliação; um saber, de novo, instalado nas competências e habilidades.

Ao pensar nos processos de ensino e de aprendizagem colados na via do a-mor, enquanto negação da morte e potência de vida, o ensinar e o aprender, necessariamente, não são binômios. Como já dizia Clarice Lispector (1998): "Aprendo contigo, mas você pensa que eu aprendi com suas liçóes, pois não foi, aprendi o que você nem sonhava em me ensinar" (LISPECTOR, p. 157). Assim, aprender não tem relação direta com o ensino, e o ensino, por sua vez, não está colado na figura do professor. Conforme Deleuze "[...] nunca se sabe de antemáo como alguém vai aprender [...]” (DELEUZE, 2006, p. 237).

Aprender e ensinar, como sinaliza Silvio Gallo (2012), no texto intitulado "As múltiplas dimensôes do aprender", referendando Deleuze, é um acontecimento, 
uma passagem, demanda presença, demanda que o aprendiz se coloque por inteiro. Ensinar e aprender é deixar-se afetar, é relacionar-se com o outro - o outro objeto, o outro pessoa. Instala-se, aí, um caso de amor ao mundo; amar, para Larrosa (2018), é se sentir atraído por mundos "[...] dos quais não fazemos parte, mas que de alguma forma nos são oferecidos e nos convidam a entrar em si. [...] não há descoberta de um mundo que não tenha sua origem em um tipo de arrebatamento amoroso [...]" (LARROSA, 2018, p. 100).

Aqui, precisamos do corpo para aprender, um corpo vivo, que se movimenta, que habita espaços e tempos, que inventa. Não se trata de um saber pertencente e absorvido pelo indivíduo, um saber técnico, quantitativo, avaliável, mas um saber sensível, um saber que inventa novas possibilidades. Um saber que não está na pessoa, mas coloca-se à mesa, como bem público; um saber que não resolve problemas e dá soluçóes empreendedoras, mas um saber singular, inventivo, produtor de experimentaçóes de vida - um saber que se produz no e pelo amor ao mundo.

Mas, para tanto, para que tempo-espaço pelo amor ao mundo seja impelido a existir, há que se insistir numa forma-escola que desloca o aluno da sua posição social, que cultiva outra passagem de tempo: não o cronológico, do relógio, da produtividade, mas o tempo ocioso, do tempo destinado a se exercitar para pensar sobre as coisas do mundo, apartado de um tempo da família e de um tempo do trabalho (MASSCHELEIN; SIMONS, 2014). Para Larrosa (2018), “[...] o mundo da escola também tem o direito de se chamar de mundo, especialmente quando na escola ocorre outra maneira de suceder (ou de abrir-se, ou de mostrar-se) o mundo" (LARROSA, 2018, p. 105)

Uma forma-escola que possa garantir tempo para o pensamento, em que o protagonista seja o conhecimento, conhecimento sem aplicabilidade. Uma formaescola que oportunize condiçóes de pensamento para todos os alunos. A escola é pensada como dispositivo para criar relaçóes interessantes entre àqueles recémchegados ao mundo (ARENDT, 1990) e àqueles que já estáo neste mundo, ensaiando um duplo movimento. Relaçóes de amor, de mostrar que viver vale à pena. A escola seria, sob este ponto de vista, um espaço e tempo que recolhe as crianças do mundo social para oferecer-lhes outros mundos possíveis.

\section{APONTAMENTOS FINAIS}

Retomando as perguntas que abriram esse texto e passando pelos três movimentos que ensaiamos, coreografados pelo aprender, ensinar e amar, nos indagamos, ao final: como pensar a escola, então? Quais os requisitos para se movimentar os processos de ensinar e aprender? O que se faz imprescindível nesse processo? Sugerimos, juntamente com os autores estudados, pensar a escola como suspensão, fazendo movimentar nela processos de ensinar e aprender pela via do amor. A-mor como o contrário de morte, como investimento, potência de vida: uma apresentaçáo do mundo e de sua potência vital. $\mathrm{O}$ amor e suas ressonâncias na docência passaria por intensificar a potência de vida a partir do que se ensina. 
Fundamentadas em tais provocaçóes, é que ousamos produzir este escrito, que procura tensionar o ensinar, o aprender e o amor na docência, enquanto elementos centrais para pensar a escola.

Num tempo em que as escolas e seus respectivos professores são constantemente convidados a repensar, nomear, definir aquilo que os estudantes aprendem (centralidade, aqui, posta na aprendizagem), objetivamos trazer à tona provocaçóes ao nosso pensar acerca dos processos de ensinar a aprender, para além da prescrição e dos resultados de aprendizagem. Quando afirmamos que aprender e ensinar é um caso de amor ao mundo, queremos dar à escola um espaço-tempo específico e essencial nas nossas vidas. É na escola, e somente na escola, que professores e estudantes assumem tais funções; tais funçôes só são possíveis de serem assumidas pois no "entre" está em movimento a matéria, o conhecimento, os saberes próprios da escola, postos à mesa. Colocamos "à mesa" àquilo que as geraçóes atuais e passadas fizeram ter sentido e, por meio desta repetiçáo de mundos já possíveis, nascem as imprevisibilidades de tantos outros mundos possíveis, tantos outros conhecimentos possíveis. As formas docentes de amar o mundo, talvez, oportunizam condiçóes para que os processos de ensinar e aprender tenham mais sentido para as crianças e os adolescentes que vivem, cotidianamente, parte de suas vidas na escola.

O processo de teorizar e refletir sobre as formas de pensar a educação "para além da aprendizagem", de pensar "o que faz da escola ser uma escola", por meio da leitura dos textos de Gert Biesta e Jorge Larrosa, juntamente com vários outros autores que compóem o "Elogio da Escola", foi tratado como uma das possibilidades de potencializar uma voz pedagógica no espaço escolar. Ele não se encerra com este trabalho, pois pode ser articulado a novas questóes que venham dinamizar fazeres pedagógicos, propondo novas inquietaçōes no ato de aprender e ensinar. Ao defender a escola e uma educação que vá ao encontro do outro, com novas formas de estarmos juntos, queremos ver e sentir o mundo de uma forma mais sublime e diferenciada, que possa imobilizar e "suspender", mesmo que provisoriamente, o tempo. E seguir amando...

\section{REFERÊNCIAS}

ARENDT, Hannah. Entre o passado e o futuro. Tradução de Mauro W. Barbosa. 5. ed. São Paulo: Perspectiva, 1990.

BANKSY. Guerra e spray. Rio de Janeiro: Intrínseca, 2012.

BIESTA, Gert. Para além da aprendizagem: educação democrática para um futuro humano. Belo Horizonte: Autêntica, 2013.

DELEUZE, Gilles. Diferença e repetiçáo. Rio de Janeiro: Graal, 2006.

ELLSWORTH-JONES, Will. The story behind Banksy. Smithsonian Magazine, February, 2013 
GALLO, Sílvio. As múltiplas dimensões do aprender. Congresso de Educação Básica: Aprendizagem e Currículo. Secretaria Municipal de Educação da Prefeitura de Florianópolis. Universidade Federal de Santa Catarina, Florianópolis, SC. 07/02/2012.

LISPECTOR, Clarice. Uma aprendizagem ou o livro dos prazeres. Rio de Janeiro: Rocco, 1998.

KOHAN, Walter Omar. O mestre inventor: relatos de um viajante educador. Belo Horizonte: Autêntica, 2015.

LARROSA, Jorge; KOHAN; Walter Omar. Apresentação da coleção. In: BIESTA, Gert. Para além da aprendizagem: educação democrática para um futuro humano. Belo Horizonte: Autêntica, 2013. p. 05-06.

LARROSA, Jorge; MASSCHELEIN, Jan; SIMONS, Maarten. A escola: formas, gestos e materialidades. In: LARROSA, Jorge (Org.). Elogio da Escola. Belo Horizonte: Autêntica, 2017. p. 195-221.

LARROSA, Jorge (Org.). Elogio da Escola. Belo Horizonte: Autêntica, 2017.

MASSCHELEIN, Jan; SIMONS, Maarten. Em defesa da escola: uma questão pública. Belo Horizonte: Autêntica, 2014.

ROUSSEAU, Jean-Jacques. Emílio ou da Educação. $3^{a}$ ed. São Paulo: Editora Difel, 1979. 